\title{
TeMPerature-Responsive POlyMers for Biological APPliCATIONS
}

\author{
M. Rackaitis and E. Manias \\ Materials Science \& Engineering Departmrnt, \\ 325-D Steidle Building \\ The Pennsylvania State University, University Park, PA 16802, U.S.A
}

\begin{abstract}
Water soluble polymers with tunable lower critical solution temperature (LCST) are of increasing interest for biological applications such as cell patterning, smart drug release, DNA sequencing etc. The present study addresses control of the polymer temperature response in water by varying chemical composition of the monomer. In order to achieve this a series of polymers were designed and synthesized based on an ethyleneoxide/ethylene monomer (EO/EE). Polymers were synthesized using polycondensation reactions of difunctional $\mathrm{m}-\mathrm{EO}$ and n-EE oligomers. The cloud point follows linearly the balance of hydrophobic/hydrophilic interaction and can be tailored in the range of $7-70^{\circ} \mathrm{C}$ by varying the $\mathrm{m} / \mathrm{n}$ composition and polymer type. Polymer grafting onto the silicon surface exhibits similar solubility behaviour. Adhesion energy measurements show that grafted polymers have solubility cloud points at the temperatures that are close to the ones of the bulk polymer solutions.
\end{abstract}

\section{INTRODUCTION}

Advance of biological and medical research demand of intelligent polymer materials for applications such as smart and/or controlled drug delivery [1, 2, 3], controlled cell patterning $[4,5,6]$, DNA separation and sequencing [7, 8] and others. Many such applications rely on smart polymer response to the external stimuli such as $\mathrm{pH}$, temperature, irradiation [9]. For example Sauer et al. [10] reports synthesis of $\mathrm{pH}$ sensitive nanocontainers based on poly(acrylic acid) which show a reversible $\mathrm{pH}$ and ionic strength dependent swelling transition in water. Reported hydrodynamic radius change is from $45 \mathrm{~nm}$ to $195 \mathrm{~nm}$ when solution $\mathrm{pH}$ changes from 3 to 9 . Zha et al. [11] report fabrication of temperature sensitive microcontainers based on crosslinked poly $(\mathrm{N}-$ isopropylacrylamide) (PNIPAM). Reported change of hydrodynamic diameter is from $450 \mathrm{~nm}$ to $250 \mathrm{~nm}$ with the LCST occuring at around 32 degrees. Buchholz et al. [8] report of DNA sequencing using poly(N,N-diethylacrylamide - co - N,N-dimethylacrylamide) matrixes that significantly change viscosity upon reaching phase transition temperature. Such thermaly controlled switch eanbles acceleration of microchannel flow by 3 orders of magnitude that allows for significant improvement of sequencing efficiency of DNA analysis. Cell patterning, biorecognition and biosensor technolgy rely on the interaction of synthetic material and biological surfaces. Surfaces that undergo rapid shifts in surface properties with small external changes are of particular interest [12].

Temperature - sensitive solubility usually originates from the existence of a lower critical solution temperature (LCST) beyond which the polymer becomes insoluble in water. Such behavior is typical for the polymers that form hydrogen bonds to water [12, 
14]. Taylor and Cerankowski [14] predicted that LCST of a water soluble polymer can be varied by controlling balance of hydrophilic and hydrophobic segments in the polymer chain. However, to date most polymers studied are based on a single homopolymer (PNIPAM), that exhibits LCST at $32^{\circ} \mathrm{C}[15]$, and efforts to change its LCST mostly involved modifications through addition of hydrophobic branches [15, 16, 17]. These branched polymers exhibit cloud points (CP) that do not correlate with the hydrophobic/hydrophilic balance of the polymer[15]. This behavior originates from the branched molecular architecture of these materials, which results in a coil to micelle "phase transition", rather than a polymer solution (LCST) phase transition. Bokias et al. [16] showed that increasing the length of the hydrophobic side chains can shift the LCST of PNIPAM, but now the phase transition broadens and occurs over a wide temperature range. Virtanen et al.[17], investigating PNIPAM modified with polyethylene oxide (PEO) grafts, also found the same broadening of phase transition, which they attributed to the collapsed aggregate formation -a micelle that consists of a PNIPAM/PEO core with a PEO shell. Such coil to micelle transitions make it difficult to predict the behavior of branched-modified thermosensitive polymers, based on the balance of hydrophilic and hydrophobic molecular segments [15], thus limiting dramatically the ability to design polymers with tailored temperature response in aqueous solutions.

The aim of this study is to design water-soluble polymers with a controlled temperature response in aqueous solutions, and to tailor their phase separation through the balance of hydrophilic and hydrophobic segments. Furthermore, synthesized polymers were grafted on inorganic (silicon) substrates and their temperature response was evaluated.

\section{EXPERIMENTAL}

\section{Monomer design}

Poly(ethylene oxide) (PEO) is one of the most studied biocompatible polymer which exhibits LCST behavior $[13,18,19]$. However its LCST is above $100^{\circ} \mathrm{C}$, which limits its use as a temperature sensitive polymer. In order to lower the LCST of PEO we synthesized an alternating copolymer of ethylene oxide and ethylene [20]. Strict alternation of hydrophilic and hydrophobic groups allowed for the prevention of micelle formation and ensured sharp and predictable phase transition at desired temperatures. Synthesized polymers have the following generic structure:

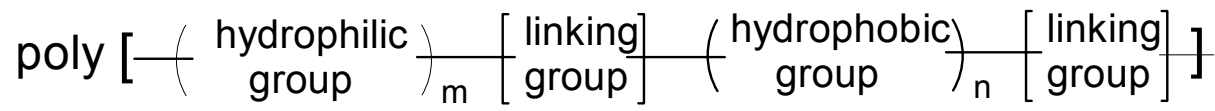

Specifically, series of polymers were designed and synthesized based on an ethyleneoxide/hydrophobic monomer with different hydrophobic and linkage groups (fig. 1). The monomer composition $(\mathrm{m} / \mathrm{n})$ allows for the tailoring of the hydrophobic/hydrophilic balance in the monomer, and in the polymer, and is the single parameter that affords tailoring of the temperature response; changing the chemistry of the hydrophobic monomer part or the chemistry of the linkage does not limit the ability to systematically 
control the polymer's transition temperature [20]. Detailed synthesis procedure of the polymers shown in figure 1 is reported in [20].

$$
\begin{aligned}
& \text { poly }\left[\left(\mathrm{O}-\mathrm{CH}_{2}-\mathrm{CH}_{2}\right)_{\mathrm{m}} \mathrm{O}-\mathrm{O}-\mathrm{O}-\left(\mathrm{CH}_{2}-\mathrm{CH}_{2}\right)_{\mathrm{n}} \stackrel{\mathrm{O}}{\mathrm{C}}-\mathrm{f}\right. \\
& \text { poly } \left.\mathrm{C} \mathrm{CH}_{2}-\left(\mathrm{O}-\mathrm{CH}_{2}-\mathrm{CH}_{2}\right) \underset{m}{\mathrm{~m}} \mathrm{CH}_{2}-\stackrel{\mathrm{O}}{\mathrm{C}}-\mathrm{O}-\left(\mathrm{CH}_{2}-\mathrm{CH}_{2}\right)_{\mathrm{n}} \mathrm{O}-\stackrel{\mathrm{O}}{\mathrm{C}}\right\}
\end{aligned}
$$

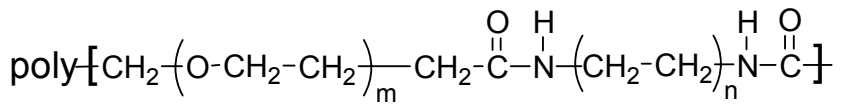

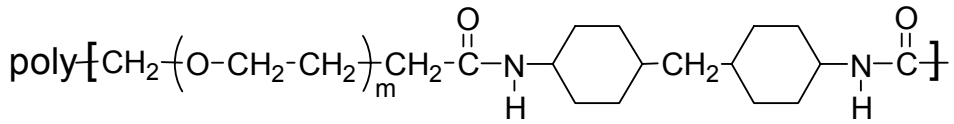

Figure 1. The chemical formulae of the temperature-responsive polymers.

\section{$\underline{\text { Temperature response }}$}

The experimental cloud point measurement curves as a function of the monomer composition of the $1 \mathrm{wt} \%$ bulk polymer solutions of are given in fig. $2 \mathrm{a}$.
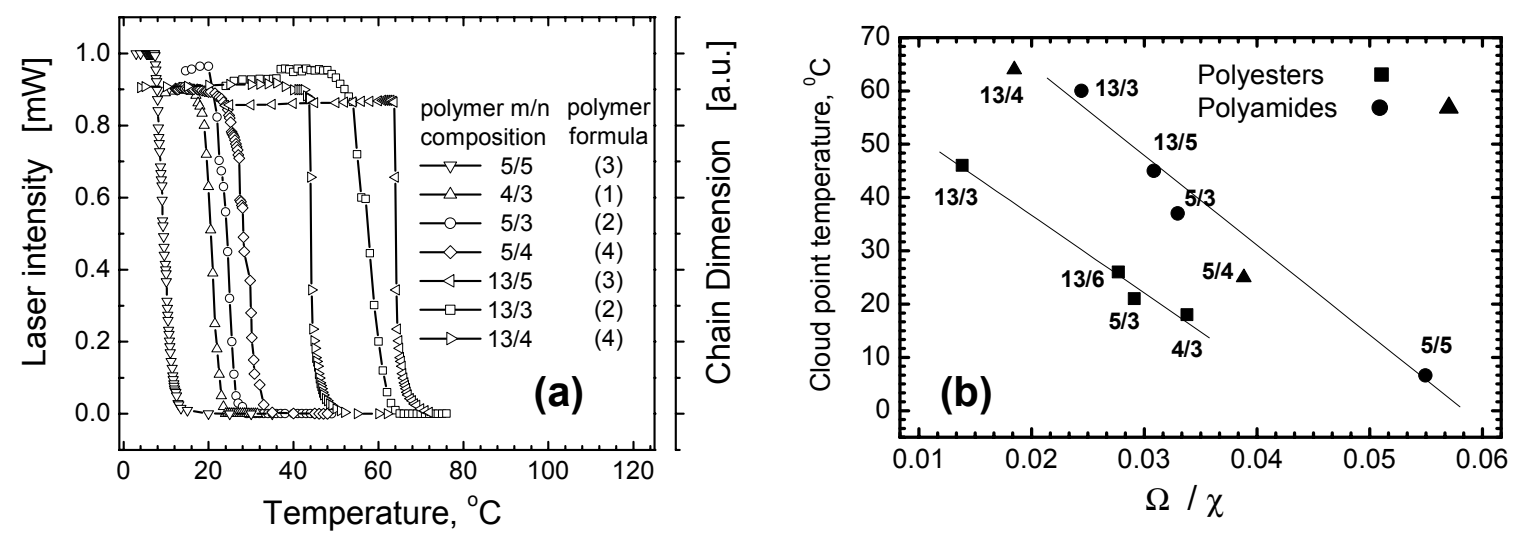

Figure 2. (a) The conformational changes of various polymer in aqueous solutions, as quantified by laser light transmittance (cloud point measurement). The polymer formulae are given in figure 1. (b) Cloud point temperature dependence on the balance of hydrophobic/hydrophilic interactions.

From the experimental data it is clear that the synthesized polymers have very sharp solubility phase transition. This suggests that the collapsed coils do not form micelles, as is the case with branched or random/block copolymers. The sharpness of the phase separation suggest that our polymer's solubility is governed by the LCST behavior of the ethyleneoxide. 
Figure $2 \mathrm{~b}$ shows experimental cloud point temperature dependence on the balance of hydrophobic/hydrphilic interactions [20]. It is clear that the cloud point follows linearly the balance of hydrophobic/hydrophilic interactions and can be tailored in the range of $7-70^{\circ} \mathrm{C}$ by varying the $\mathrm{m} / \mathrm{n}$ composition and polymer type. It should be also stressed that changing the chemistry of the hydrophobic monomer part or the chemistry of the linkage does not limit the ability to systematically control the polymer's transition temperature.

\section{Polymers grafted on the surface}

Polyesters of the formulae (2) having hydrophilic/hydrophobic balance $(\mathrm{m} / \mathrm{n})$ of $13 / 6$ and 13/3 where grafted on the silicon surface modified with aminopropyltriethoxysilane (APTES) self assembled monolayer (SAM). SAM was prepared by immersion of silicon wafers into $0.4 \mathrm{wt} \%$ solution of APTES in toluene after that the surface was curred in vacuum according to the procedure reported in [21]. In order to control the grafting density of the polymer brushes SAM modified silicon was immersed into the mixture of myristic acid chloride and in mixture solution in chloroform of myristic acid chloride and dichlorocarboxymethyl ether. Ratio of the mixture determined the grafting density of the polymer. Polycondensation polymerization was done by sequential immersion of the prepared surface into the monomer solutions as it is shown in fig. 3 a. A robot (fig. $3 \mathrm{~b}$ ) was designed and assembled for the automatic sequence and timing control. The procedure ensured monomer by monomer growth of the polymer which allowed for precise control of the molecular weight of the brushes.

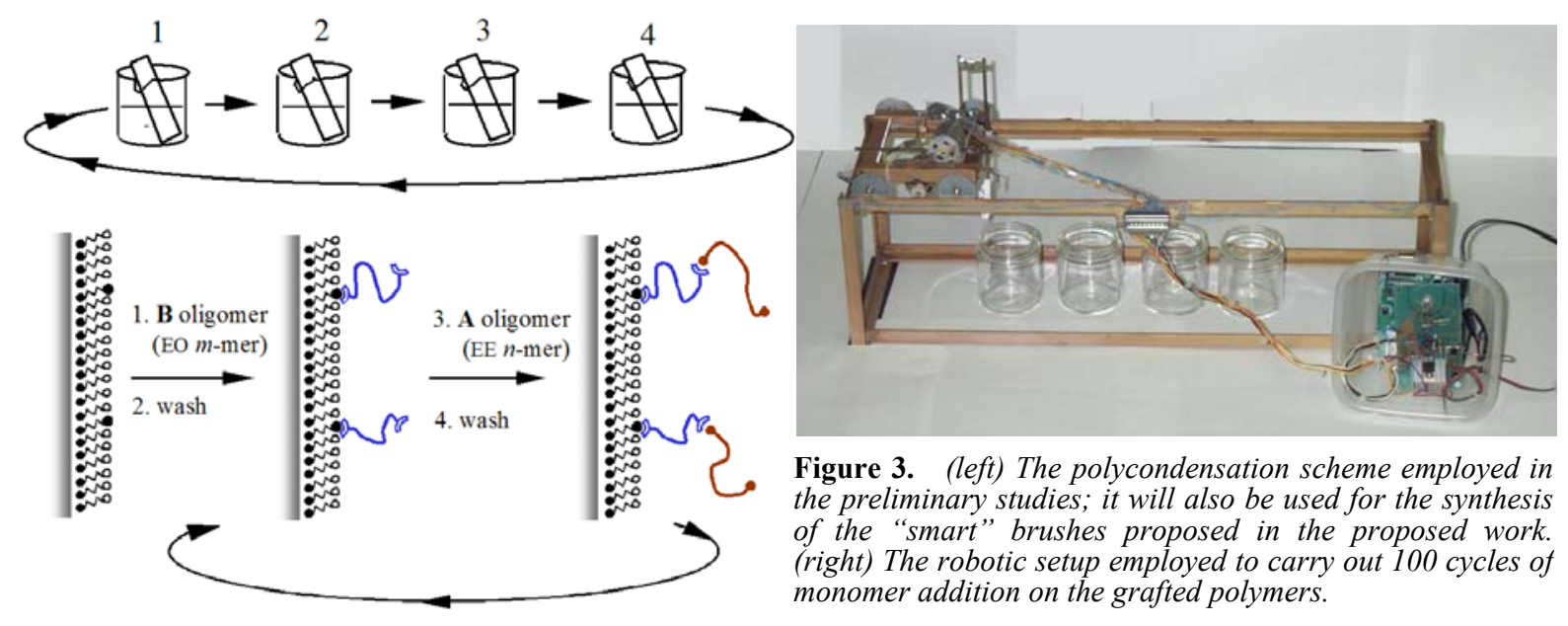

Temperature response of the polymer on the surface was evaluated by static contact angle and by determination of surface adhesion energy using AFM. Measurement results are given in table I. 
Table I. Contact angle and adhesion energies (AFM)

\begin{tabular}{|c|c|c|c|c|}
\hline Polymer & $\begin{array}{c}\text { Contact angle } \\
\text { (below LCST) }\end{array}$ & $\begin{array}{c}\text { Contact angle } \\
\text { (above LCST) }\end{array}$ & $\begin{array}{c}\text { Adhesion energy } \\
\text { (below LCST) } \\
\text { mJ }\end{array}$ & $\begin{array}{c}\text { Adhesion energy } \\
\text { (above LCST), } \\
\text { mJ }\end{array}$ \\
\hline $13 / 3\left(47^{\circ} \mathrm{C}\right)$ & $28^{\circ}\left(25^{\circ} \mathrm{C}\right)$ & $55^{\circ}\left(65^{\circ} \mathrm{C}\right)$ & $0.62\left(25^{\circ} \mathrm{C}\right)$ & $0.25\left(55^{\circ} \mathrm{C}\right)$ \\
\hline $13 / 6\left(27^{\circ} \mathrm{C}\right)$ & $58^{\circ}\left(23^{\circ} \mathrm{C}\right)$ & $75^{\circ}\left(65^{\circ} \mathrm{C}\right)$ & $0.60\left(15^{\circ} \mathrm{C}\right)$ & $0.10\left(45^{\circ} \mathrm{C}\right)$ \\
\hline
\end{tabular}

Contact angle was measured using hot deionized distilled water droplet of $5 \mu \mathrm{L}$. The droplet was left to cool down while measurements were made. Its temperature was determined from heat transfer calculations.

Surface adhesion energy was calculated from the measured force - separation curves using the method reported in [22]. The AFM tip was modified by adding a tungsten microsphere to it. The diameter of the microsphere was determined by optical microscope and was $18 \mu \mathrm{m}$. This allowed for better evaluation of the surface adhesion energy (fig. 4) since the diameter of microsphere and thus contact area was determined experimentally.

From the data reported in table I it is clear that the polymers grafted to the surface exhibit transitions that parallel the bulk polymer LCST solution-behavior. LCST of the surface grafted polymer chain is close to the bulk polymer solution LCST. Finally, the collapse of the grafted polymers can be directly imaged via tapping mode AFM under water and varied temperature (fig. 4 ).
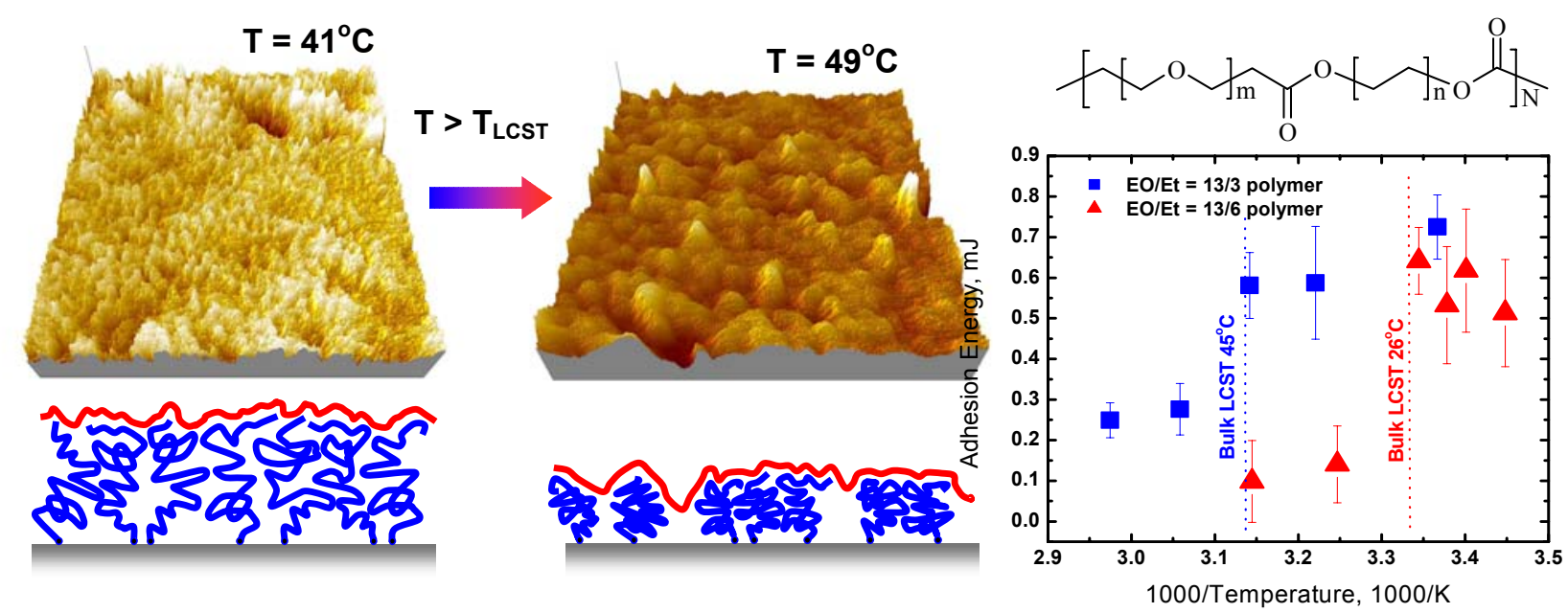

Figure 4 Transition of an end-tethered polymer brush as observed by AFM. (Left) A direct observation of the chain conformation collapse upon crossing the LCST temperature $(\mathrm{m} / \mathrm{n}=13 / 3$ EO/Et, scanning size $500 \times 500 \mathrm{~nm}$, height scale $10 \mathrm{~nm}$ ). (Right) The accompanying changes in adhesion for the same brush (blue squares), as well as for a second polymer (red triangles, $m / n=13 / 6$ EO/Et), using a tip bearing a colloidal particle of $10 \mu \mathrm{m}$ in diameter (contact area of ca. $1 \mathrm{\mu m}^{2}$, height scale $5 \mathrm{~nm}$ ). 


\section{CONCLUSIONS}

Experimental data show that synthesized polymers are temperature responsive and their phase transition temperature has linear dependence on the balance hydrophobic / hydrophilic interactions. This originates from the linear structure of the polymers.

Carefully choosing the balance and type of the polymer it is possible to tune phase transition at the desired temperature. Our experimental data show tuning possibility in the range of $7-70^{\circ} \mathrm{C}$.

Polymer chains grafted on the silicon surface retain their temperature responsive properties and show phase transition at temperatures close to the ones measured for bulk solutions. Choosing polymer type and composition it is possible to tune desired surface adhesion energy switching which is important for biological applications such as cell patterning.

Synthesized polymers can be a new class of biocompatible temperature sensitive polymers.

\section{REFERENCES}

1. Hatefi A., Amsden B., J. Control. Release, 80, 9-28 (2002).

2. Jeong B., Choi Y.K., Bae Y.H., Zentner G., Kim S.W., J. Control. Reslease, 62, 109114 (1999).

3. Lavasanifar A., Samuel J., Kwon G.S., J. Biomed. Mater. Res. 52, 831-835 (2000).

4. Chen G., Imanishi Y., Ito Y., J. Biomed. Mater. Res., 42, 38-44 (1998).

5. Folch A., Toner M., Annu. Rev. Biomed. Eng., 2, 227-256 (2000).

6. Liu V. A., Jastromb W.E., Bhatia S.N., J. Biomed. Mater. Res., 60, 126-134 (2002).

7. Albarghouthi M.N., Barron A. E., Electrophoresis, 21, 4096-4111 (2000).

8. Buchholz B.A., Doherty E.A.S., Albarghouthi M.N., Bogdan F.M., Zahn J.M., Barron A.E., Anal. Chem., 73, 157-164 (2001).

9. Lowe A.B., McCormick C.L., in ACS Symposium Series 780, 1-13 (2001).

10. Sauer M., Streich D., Meier W., Adv. Mater., 13(21), 1649-1651 (2001).

11. Zha L., Zhang Y., Yang W., Fu S., Adv. Mater., 14(15), 1090-1092 (2002).

12. Catner D.G., Buddy D.R., Surface Science, 500, 28-60 (2002).

13. Dormidontova E.E., Macromolecules, 35, 97-101 (2002).

14. Taylor L.D., Cerankowski L.D. J. Polym. Sci. Polym. Chem. Ed., 13, 2551-2570 (1975).

15. Laschewsky, A.; Rekai, El D.; Wischerhoff, E. Macromol. Chem. Phys., 202, 276 286 (2001).

16. Bokias, G.; Hourdet, D.; Iliopoulos, I. Macromolecules, 33, 2929 - 2935 (2000).

17. Virtanen, J.; Baron, C.; Tenhu, H. Macromolecules, 33, 336 - 341 (2000).

18. Lee J.H., Lee H.B., Andrade J.D., Prog. Polym. Sci., 20, 1043-1079 (1995).

19. Bekiranov S., Bruinsma R., Pincus P., Phys. Rev. E, 55(1), 577-585 (1997).

20. Rackaitis M., Strawhecker K., Manias E., J. Polym. Sci. B: Polym. Phys., 40, 23392342 (2002).

21. Vandenberg, E.T.; Bertilsson, L.; Liedberg, B.; Uvdal, K.; Erlandsson, R.; Elwing, H.; Lundström I. , J. Colloid \& Interface Sci., 147(1), 103-118 (1991).

22. Burnham, N.A.; Colton, R.J.; Polock, H.M. Nanotechnology, 4, 64-80 (1993). 